\title{
No effects of high-dose omeprazole in patients with severe airway hyperresponsiveness and (a)symptomatic gastro- oesophageal reflux
}

\author{
M.J. Boeree*, F.T.M. Peters**, D.S Postma*, J.H. Kleibeuker**
}

No effects of high-dose omeprazole in patients with severe airway hyperresponsiveness and (a)symptomatic gastro-oesophageal reflux. M.J. Boeree, F.J.M. Peters, D.S. Postma, J.H. Kleibeuker. (CERS Journals Ltd 1998.

ABSTRACT: Acid gastro-oesophageal reflux may aggravate respiratory symptoms in patients with asthma and chronic obstructive pulmonary disease (COPD) by increasing airway hyperresponsiveness through vagally-mediated pathways. We wanted to determine whether elimination of acid reflux could improve symptoms in such patients.

In a randomized, double-blind, placebo-controlled study, 36 allergic and nonallergic subjects (17 males and 19 females, mean age $52 \mathrm{yrs}$ ), with airway obstruction and severe airway hyperresponsiveness despite maintenance treatment with an inhaled corticosteroid and with increased acid gastro-oesophageal reflux, were treated either with omeprazole, $40 \mathrm{mg}$ b.i.d., or placebo for 3 months. Primary endpoints were: airway hyperresponsiveness, as determined by the provocative concentration of methacholine producing a $20 \%$ fall in forced expiratory volume in one second (PC20); and airway obstruction. Secondary endpoints were: peak expiratory flow variability; reversibility to inhaled ipratropium bromide as a parameter of vagal activity; asthma symptoms scores; and medication used. Reflux was measured by $24 \mathrm{~h}$ ambulatory intraoesophageal pH measurement.

Omeprazole, $40 \mathrm{mg}$ b.i.d., for 3 months had no beneficial effect on any of the pulmonary parameters, despite its profound effect on acid reflux and improvement of reflux symptoms scores, compared to placebo.

The results of this study do not support a role for intensive antireflux therapy to improve pulmonary symptoms and function in patients with asthma and chronic obstructive pulmonary disease, who have severe airway hyperresponsiveness despite maintenance treatment with inhaled corticosteroids.

Eur Respir J 1998; 11: 1070-1074.
Depts of *Pulmonary Medicine and **Gastroenterology, University Hospital, Groningen, The Netherlands.

Correspondence: D.S. Postma

Dept of Pulmonary Medicine

University Hopital

Hanzeplein 1

9713 GZ Groningen

The Netherlands

Fax: 31503619320

Keywords: Acid gastro-oesophageal reflux airway hyperresponsiveness

omeprazole

Received: January 41997

Accepted after revision November 251997

Supported by Astra Pharmaceutica B.V., Zoetermeer, The Netherlands.
Many patients with asthma and chronic obstructive pulmonary disease (COPD) are frequently affected by an increase in symptoms and airways obstruction. Several triggers can exacerbate the disease by eliciting smooth muscle contraction, airway inflammation, airway wall oedema and hypersecretion of mucus. One such factor may be gastrooesophageal reflux (GER). The incidence of GER among asthmatics exceeds that of the general population, reportedly ranging 40-80\% [1-3], thereby constituting a possibly important factor for the instability of the disease. Potential mechanisms underlying GER-induced airway symptomatology are thought to be microaspiration of acid into the airways with subsequent induction of an inflammatory response and bronchoconstriction, or stimulation of acid sensitive receptors in the oesophageal wall. The latter may either cause bronchoconstriction mediated by a direct vagal reflex or increase airway hyperresponsiveness through vagally-mediated pathways [3-8].

Short-term experiments exploring the above mechanisms have focused on microaspiration and a direct vagal reflex. These studies have shown conflicting results. The same is true for long-term studies. Some studies have indicated that pulmonary symptoms and lung function can be improved by intensive treatment of acid reflux, both by surgery and medical treatment [9-13]; however this has not been confirmed in other studies $[14,15]$. The discrepancy between outcomes may result from the fact that these studies did not consider airway hyperresponsiveness as an inclusion criterion or an end parameter. This may have affected the results, since oesophageal acid perfusion may be associated with an increase in airway hyperresponsiveness [16]. Furthermore, most studies have lacked objective measurements of the effect of antireflux measures, and negative results with respect to pulmonary function may have been due to insufficient antireflux therapy.

The aim of the present study was to investigate whether patients with severe airway hyperresponsiveness despite treatment with inhaled corticosteroids would benefit from the most effective medical treatment for acid reflux, i.e. a proton pump inhibitor in a high dose (omeprazole, $40 \mathrm{mg}$ b.i.d.). Subjective and objective measures of clinical pulmonary stability were assessed by recording symptoms, 
peak expiratory flow (PEF), spirometry and airway hyperresponsiveness to methacholine. The effectiveness of treatment with respect to reflux was measured by $24 \mathrm{~h}$ registration of intraoesophageal $\mathrm{pH}$.

\section{Patients and methods}

\section{Patients}

Allergic and nonallergic individuals, aged 18-80 yrs, with airway obstruction and severe airway hyperresponsiveness (i.e, provocative concentration of methacholine bromide causing a Š20\% fall in forced expiratory volume in one second (PC20) of less than $2 \mathrm{mg} \cdot \mathrm{mL}^{-1}$ ), despite maintenance treatment with an inhaled corticosteroid of at least $0.4 \mathrm{mg} \cdot \mathrm{day}^{-1}$, were eligible for this study when there was: documented increased acid reflux (vice infra); and a baseline forced expiratory volume in one second (FEV1) $>1.25 \mathrm{~L}$. None of the subjects had an upper and/or lower respiratory tract infection or used oral corticosteroids during the 2 months prior to the study. No participant used antireflux medication during the last month prior to the study, with the exception of antacids. Patients with other concomitant lung diseases were excluded from the study. All patients gave written informed consent and the study was approved by the hospital's Medical Ethics Committee.

\section{Study design}

The study was performed in a randomized, doubleblind, placebo-controlled parallel manner. Participants were stratified for their PC20, i.e. Š 0.6 and $<0.6 \mathrm{mg} \cdot \mathrm{mL}^{-1}$. Allocation to either of the groups was performed using a computer-generated randomization list. The stratification procedure resulted in a good balance in PC20 values over the omeprazole and placebo groups. Subjects received either omeprazole, $40 \mathrm{mg}$ b.i.d., or placebo for 12 weeks. Initial studies included a reversibility test with ipratropium bromide $(40 \mu \mathrm{g})$, and intraoesophageal $24 \mathrm{~h} \mathrm{pH}$ measurement. To investigate the possibility of a direct effect of omeprazole on hyperresponsiveness, PC20 was assessed prior to the study on two separate days, $1-3 \mathrm{~h}$ after omeprazole $40 \mathrm{mg}$ and placebo, respectively, in a double-blind, randomized fashion. Patients visited the outpatient clinic at baseline and every 4 weeks.

During the week before each visit, PEF values were recorded at home with a mini-Wright peak flow meter, and pulmonary symptoms were scored on a four point scale every morning and evening. Spirometry was performed every 4 weeks during the study. The reversibility test, intraoesophageal $24 \mathrm{~h} \mathrm{pH}$ measurement, and responsiveness to methacholine were assessed again at the final visit. Compliance was assessed by counting capsules every 4 weeks.

\section{Methods}

Twenty four hour ambulatory intraoesophageal $\mathrm{pH}$ measurement was performed with a glass $\mathrm{pH}$ electrode (Ingold, Urdorf, Switzerland) $5 \mathrm{~cm}$ above the lower oeso- phageal sphincter, which was localized manometrically using a solid state pressure transducer (Gaeltec Ltd, Isle of Skye, UK). Data were stored in a solid state memory device (Gastrograph Mark II; Fresenius GmbH, Oberursel, Germany), and were analysed with a computer-assisted program (analysis program Gastroware; MIC A.G., Solothurn, Switzerland) with respect to total, upright and supine time with $\mathrm{pH}<4.0$. Increased GER was defined as $>4 \%$ of $24 \mathrm{~h}$ registration with $\mathrm{pH}<4.0$, or $>3 \%$ during the supine position $[17,18]$.

Spirometry was performed using a calibrated, watersealed spirometer (Lode BV, Groningen, the Netherlands). FEV1 and inspiratory vital capacity (IVC) were measured until three reproducible measures $(<5 \%$ difference) were obtained and the highest values were used. Reversibility of airway obstruction was tested with FEV1 measurements before and $45 \mathrm{~min}$ after two single inhalations of $20 \mu \mathrm{g}$ of ipratropium bromide (Atrovent ${ }^{\circledR}$; Boehringer Ingelhelm, Germany) from a metered-dose inhaler, administered by a volume chamber. Reversibility is expressed as the absolute increase in FEV1 as\% predicted (ýFEV1\% pred).

A methacholine challenge test was performed with a DeVilbiss 646 Nebulizer (DeVilbiss Health Care Inc., Somerset, PA, USA) at a flow rate of $8 \mathrm{~L} \cdot \mathrm{min}^{-1}$, calibrated to $0.12 \mathrm{~mL} \cdot \mathrm{min}^{-1}$ output. Methacholine bromide solutions were prepared in phosphate-buffered saline (in doubling concentration 0.038-19.6 mg.mL-1; Sigma Chemical Co., St Louis, MO, USA). The best of three FEV1 attempts was taken as baseline FEV1. Solutions were nebulized during 2 min tidal breathing at 5 min dosing intervals. FEV1 was measured 30 and $90 \mathrm{~s}$ after each dose. The test was stopped when FEV1 fell $>20 \%$ from baseline or when the highest concentration was reached. PC20 was calculated by interpolation of the last two points on a "log-doses" versus "\% fall from baseline FEV1" scale.

PEF was assessed with a mini-Wright peak flow meter every morning upon awakening, before taking a bronchodilator if required, and every evening at bedtime, again before any bronchodilator. The highest PEF value of three blows was recorded. PEF variability was defined as diurnal variability (evening PEF - morning PEF/mean PEF of that day $\times 100 \%$ ) and day-to-day variability (co-efficient of variation of morning, evening and all values).

Patients scored pulmonary symptoms (dyspnoea, cough) during the day and night, according to the $0-3$ scale: $0=$ none; $1=$ mild (awareness of symptoms and/or signs which are easily tolerated); $2=$ moderate (some discomfort, i.e. symptoms and/or signs causing interference with daily life/ sleep); $3=$ severe (incapacitating, i.e. inability to perform usual activities or work/sleep). Similarly, the numbers and times of inhalation of bronchodilators taken during this week, were registered. Before the start of the study and at each visit, patients were asked to give an overall evaluation of their reflux symptoms if present, on a 0-3 point scale (see above). Symptoms evaluated were heartburn, regurgitation and dysphagia.

\section{Statistical analysis}

Results are presented as mean values and SD unless otherwise stated. After checking for normal distribution, differences between the treatment arms were assessed by Student's t-test. Analyses were performed based on all 
Table 1. - Data on demography, pulmonary function and reflux of the two study groups at entry into the study

\begin{tabular}{|c|c|c|c|c|c|c|}
\hline & \multicolumn{3}{|c|}{ Omeprazole group } & \multicolumn{3}{|c|}{ Placebo group } \\
\hline & Total & Reversible & Irreversible & Total & Reversible & Irreversible \\
\hline Patients $\mathrm{n}$ & 18 & 10 & 8 & 18 & 6 & 12 \\
\hline Age yrs & $51(10)$ & $52(8)$ & $51(12)$ & $52(17)$ & $44(18)$ & $56(16)$ \\
\hline $\operatorname{Sex} M / F$ & $8 / 10$ & $5 / 5$ & $3 / 5$ & $9 / 9$ & $2 / 4$ & $7 / 5$ \\
\hline Weight $\mathrm{kg}$ & $84(11)$ & $84(8)$ & $85(15)$ & $75(15)$ & $74(20)$ & $77(14)$ \\
\hline Time $\mathrm{pH}<4 \%$ total time & $12(11)$ & $14(13)$ & $8(4)$ & $9(5)$ & $9(7)$ & $8(3)$ \\
\hline FEV $1 \%$ pred & $66(20)$ & $64(21)$ & $69(19)$ & $75(23)$ & $68(19)$ & $79(25)$ \\
\hline $\mathrm{FEV}_{1} / \mathrm{VC}^{\%} \%$ & $58.7(16.0)$ & $56.0(16.8)$ & $62.1(15.3)$ & $62.0(15.7)$ & $61.9(16.2)$ & $63.2(16.4)$ \\
\hline Morning PEF L. $\min ^{-1}$ & $329(91)$ & $313(84)$ & 349 (102) & 321 (109) & $359(125)$ & $306(102)$ \\
\hline$\Delta \mathrm{FEV}_{1} \%$ pred & $11(7)$ & $14(7)$ & $6(3)$ & $9(9)$ & $18(7)$ & $4(4)$ \\
\hline $\log _{2} \mathrm{PC}_{20} \mathrm{mg} \cdot \mathrm{mL}^{-1}$ & -0.81 & -0.78 & -0.85 & -0.75 & -0.90 & -0.73 \\
\hline Geometric mean & 1.48 & 1.75 & 1.18 & 1.41 & 1.31 & 1.57 \\
\hline Dysphagia* & $2 / 1 / 0$ & $2 / 1 / 0$ & $0 / 0 / 0$ & $3 / 0 / 0$ & $1 / 0 / 0$ & $2 / 0 / 0$ \\
\hline Heartburn* & $9 / 0 / 0$ & $4 / 0 / 0$ & $5 / 0 / 0$ & $9 / 3 / 0$ & $1 / 2 / 0$ & $7 / 1 / 0$ \\
\hline Regurgitation* & $3 / 0 / 0$ & $1 / 0 / 0$ & $2 / 0 / 0$ & $4 / 3 / 0$ & $1 / 2 / 0$ & $3 / 1 / 0$ \\
\hline
\end{tabular}

Data are expressed as mean and SD in parenthesis, unless otherwise stated. *: figures $\mathrm{x} / \mathrm{y} / \mathrm{z}$ represent numbers of patients with mild, moderate and severe complaints, respectively. M: male; F: female; FEV1: forced expiratory volume in one second; \% pred: percentage of predicted value; VC: vital capacity; PEF: peak expiratory flow; $\triangle \mathrm{FEV}$ 1: improvement in FEV1 after inhaling $40 \mu \mathrm{g}$ of ipratropium bromide; PC20: provocative concentration of methacholine causing a Š20\% fall in FEV 1 ; Reversible: $\Delta$ FEV 1 Š $9 \%$ pred.

Table 2. - Lung function variables at baseline and at the end of the study in the omeprazole and placebo group

\begin{tabular}{|c|c|c|c|c|c|c|}
\hline & \multicolumn{3}{|c|}{ Omeprazole group } & \multicolumn{3}{|c|}{ Placebo group } \\
\hline & Baseline & Pts $n$ & Week 12 & Baseline & Pts $n$ & Week 12 \\
\hline$\overline{\mathrm{FEV}} 1 \mathrm{~L}$ & $2.13(0.80)$ & 16 & $2.21(0.70)$ & $2.20(0.88)$ & 14 & $2.23(0.81)$ \\
\hline$\Delta \mathrm{FEV}_{1} \%$ pred & $10.7(7.7)$ & 15 & $10.3(7.8)$ & $10.0(9.8)$ & 11 & $6.8(5.4)$ \\
\hline PEF morning $\mathrm{L} \cdot \mathrm{min}^{-1}$ & $349(83)$ & 15 & 322 (109) & $322(109)$ & 13 & 335 (98) \\
\hline PEF variability $\%$ & $4.1(6.4)$ & 15 & $3.3(4.8)$ & $8.1(8.7)$ & 13 & $9.1(12.6)$ \\
\hline
\end{tabular}

Single test results not available in case $\mathrm{n}<16$ (omeprazole) or $<14$ (placebo). Data are presented as mean, and sD in parenthesis. Pts: patients. For further definitions see legend to table 1.

patients treated. PC20 methacholine values were log transformed, one unit change representing one dose step. For change in PC20 during the study, PC20 values after placebo pretreatment were used. For diary variables, the mean of the last 7 days before each visit were used for analyses. One-way analyses of variance (ANOVA) were used for the change in a variable between baseline and the end of the study. For reflux symptom scores, a Wilcoxon rank sum test was used with treatment as classifier.

\section{Results}

Thirty six patients were enroled into the study, six discontinued the study (two in the omeprazole group and four in the placebo group), five because of an exacerbation and one was lost to follow-up. There were no significant differences in baseline characteristics between the two treatment groups. Table 1 shows the clinical characteristics of patients who were reversible (improvement Š9\% pred) or irreversible to inhaling $40 \mu \mathrm{g}$ of ipratropium bromide. Compliance was low, 13 patients having taken less than $75 \%$ of the study drugs, equally divided between the two treatment arms.

Omeprazole effectively reduced acid reflux, the proportion of time with $\mathrm{pH}<4$ was reduced from 12.2 (11.0) to $2.0(3.0) \%$, whereas in the placebo group the proportion of time with $\mathrm{pH}<4$ was 9.5 (5.1) and 7.5 (4.6)\%, respectively. In addition heartburn as a reflux symptom was significantly improved with omeprazole, nine patients in the omeprazole arm being asymptomatic at Visit 1 and 16 at Visit 4, compared to six and eight in the placebo arm, respectively. There were no significant improvements in other oesophageal symptoms, largely due to lack of symptoms at baseline (table 1).

Reversibility, FEV1, vital capacity (VC) and PEF measurements (the latter being expressed either as absolute values in morning and evening or as diurnal or day-to-day PEF variability) were not affected by omeprazole (table 2). PC20 methacholine did not change significantly after a single dose of omeprazole (fig. 1), nor after 12 weeks treatment (fig. 2). Respiratory symptoms did not significantly change apart from cough at night, overall score being $0.43(0.65)$ and $0.45(0.51)$ at Visits 1 and 4 with omeprazole and $0.78(0.74)$ and $0.42(0.64)$ with placebo, respectively.

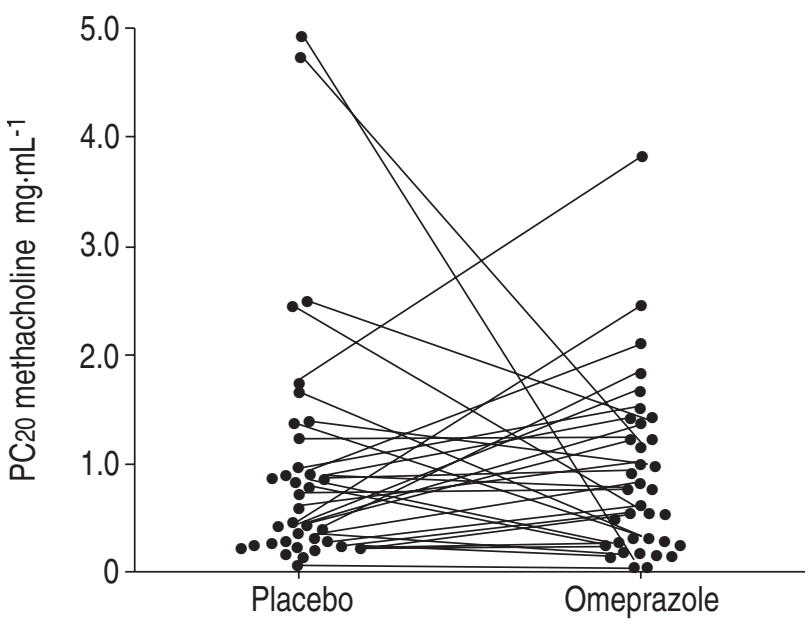

Fig. 1. - PC20 methacholine 1-3 h after placebo and a single dose of omeprazole $(40 \mathrm{mg})$. $\mathrm{PC} 20$ : provocative concentration producing a $20 \%$ fall in forced expiratory volume in one second. 

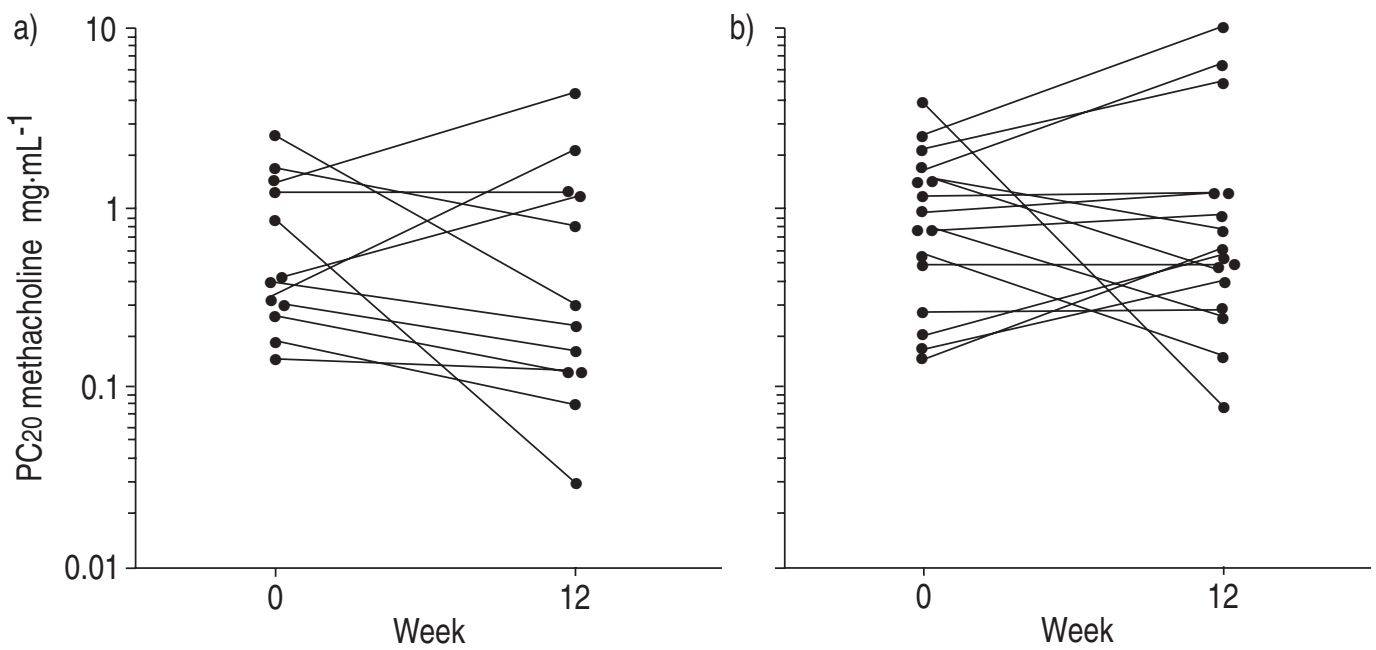

Fig. 2. - PC20 methacholine before and at the end of 12 weeks of treatment with: a) placebo (data from two patients not available); and b) omeprazole (40 $\mathrm{mg}$ b.i.d.). For definitions see legend to figure 1 .

\section{Discussion}

No clinical benefit of high-dose omeprazole could be established in this group of asthma and COPD patients with severe airway hyperresponsiveness and increased gastro-oesophageal acid reflux. These results are in contrast to those of some studies [9-13], but are comparable with those of others $[14,15]$. The failure to show any benefit in studies has been ascribed to several factors, including insufficient inhibition of acid reflux and the short duration of the study treatment. Both of these factors were taken into account in the present study; thus, other reasons for the lack of efficacy should be sought. One such factor may be the power of the study. With the observed standard deviation of the change in $\log _{2} \mathrm{PC} 20$ from baseline (1.97), 130 patients would have been needed to reach the generally accepted meaningful difference of 1.0 doubling dose with a power of $80 \%$. However, close inspection of the individual data did not reveal a trend towards improvement with omeprazole. The clinical relevance of a small positive effect when it is necessary to include such a large number (130) of individuals in a study is also doubtful. Finally, evaluation of only those individuals in the omeprazole group with effective management of reflux and those in the placebo group with repeatedly high reflux scores did not change the results.

Both nonallergic and allergic individuals were included in this study, whereas some authors suggest that specifically nonallergic asthmatics benefit from antireflux treatment $[10,19]$. Another point of criticism could be that we did not investigate only those patients with gastro-oesophageal reflux symptoms that had started before asthma symptoms appeared. Other investigators have suggested that the latter subjects are specifically the ones in whom antireflux measures are most successful with regard to improving pulmonary symptoms [19]. However, positive results have been reported to occur in other groups as well $[9,10]$. Finally, one study suggested that the effects might be better in asthmatic individuals compared with bronchitic patients [3]. Whereas all of the present patients exhibited severe airway hyperresponsiveness, only 16 of them were reversible to inhaled ipratropium bromide. However, no clinical effect was seen within the group with reversi- ble airway obstruction either, despite adequate reduction of acid reflux by omeprazole.

As to mechanisms by which acid reflux may induce worsening of asthma symptoms, this study does not provide new insights. The fact that strong inhibition of reflux for 12 weeks does not have any appreciable effect on airway hyperresponsiveness almost precludes that any effect is mediated through such a mechanism. Nevertheless, it might be that even 12 weeks of treatment was too short a duration to obtain measurable improvement and that a similar trial for a more extended period, for example a year, might be worthwhile.

In conclusion, this study does not support screening of symptomatic patients with asthma and chronic obstructive pulmonary disease with severe airway hyperresponsiveness, despite their regular use of inhaled corticosteroids, for the presence of gastro-oesophageal reflux. Though individual cases have been described who do respond to omeprazole treatment, the present results do not suggest a general role for acid suppressive therapy in patients with asthma and chronic obstructive pulmonary disease.

\section{References}

1. Allen CJ, Newhouse MT. Gastroesophageal reflux and chronic respiratory diseases. Am Rev Respir Dis 1985; 129: 645-647.

2. Sontag SJ, O'Connell S, Khanderwal S, et al. Most asthmatics have GER with or without bronchodilator therapy. Gastroenterology 1990; 99: 613-620.

3. Ducoloné A, Vandevenne A, Jouin H, et al. Gastroesophageal reflux in patients with asthma and chronic bronchitis. Am Rev Respir Dis 1987; 135: 327-332.

4. Mansfield LE, Hameister HH, Spaulding HS, Smith NJ, Glab N. The role of the vagus nerve in airway narrowing caused by intraesophageal hydrochloric acid provocation and esophageal distention. Ann Allergy 1981; 47: 431434.

5. Tuchman DN, Boyle JT, Pack AI, et al. Comparison of airway responses following tracheal or esophageal acidification in the cat. Gastroenterology 1984; 87: 872-881.

6. Tan WC, Martin RJ, Pandey R, Ballard RD. Effects of spontaneous and simulated gastroesophageal reflux on 
sleeping asthmatics. Am Rev Respir Dis 1990; 141: 1394 1399.

7. Schan CA, Harding SM, Haile JM, Bradley LA, Richter JE. Gastroesophageal reflux induced bronchoconstriction. An intraesophageal acid infusion study using stateof-the-art technology. Chest 1994; 106: 731-737.

8. Jack CIA, Calverley PMA, Donnelly RJ, et al. Simultaneous tracheal and oesophageal $\mathrm{pH}$ measurements in asthmatic patients with gastro-oesophageal reflux. Thorax 1995; 50: 201-204.

9. Kjellén G, Tibbling L, Wranne B. Effect of conservative treatment of oesophageal dysfunction on bronchial asthma. Eur J Respir Dis 1981; 62: 190-197.

10. Larrain A, Carrasco E, Galleguillos F, Sepulveda R, Pope CE. Medical and surgical treatment of nonallergic asthma associated with gastroesophageal reflux. Chest 1991; 99: 1330-1335.

11. Gustafsson PM, Kjellman N-IM, Tibbling L. A trial of ranitidine in asthmatic children and adolescents with or without pathological gastro-oesophageal reflux. Eur Respir J 1992; 5: 201-206.

12. Meier JH, McNally PR, Punja M, et al. Does omeprazole (Prilosec) improve respiratory function in asthmatics with gastroesophageal reflux? A double-blind, placebo-controlled crossover study. Dig Dis Sci 1994; 39: 2127-2133.

13. Harding SM, Richter JE, Guzzo MR, Schau CA, Alexander RW, Bradley LA. Asthma and gastroesophageal re- flux: acid suppressive therapy improves asthma outcome. Am J Med 1996; 100: 395-405.

14. Nagel RA, Brown P, Perks WH, Wilson RSE, Kerr GD. Ambulatory $\mathrm{pH}$ monitoring of gastro- oesophageal reflux in "morning dipper" asthmatics. Br Med J 1988; 297: 1371-1373.

15. Ford GA, Oliver PS, Prior JS, Butland RJA, Wilkinson SP. Omeprazole in the treatment of asthmatics with nocturnal symptoms and gastro-oesophageal reflux: a placobo-controlled, cross-over study. Postgrad Med J 1994; 70: 350-354.

16. Herve P, Denjean A, Jian R, Simmonneau G, Duroux P. Intraesophageal perfusion of acid increases the bronchomotor response to methacholine and to isocapnic hyperventilation in asthmatic subjects. Am Rev Respir Dis 1986; 134: 986-989.

17. Johnson FJ, DeMeester TR. Twenty four hour $\mathrm{pH}$ monitoring of the distal esophagus, a quantitative measure of gastroesophageal reflux. Am J Gastroenterol 1974; 62: 325-332.

18. Richter JE, Bradley LA, DeMeester TR, Wu WC. Normal $24 \mathrm{~h}$ ambulatory esophageal $\mathrm{pH}$ values. Influence of study center, pH electrode, age and gender. Dig Dis Sci 1992; 37: 849-856.

19. Perrin-Fayolle M, Gormand F, Braillon G, et al. Longterm results of surgical treatment for gastroesophageal reflux in asthmatic patients. Chest 1989; 96: 40-45. 